\title{
From the Editor of Sexuality and Disability: Taking a Broad Brush to Depict Sex, Sexuality, Behavior Involving Sex, Disability/Ability and Challenging Opportunities
}

\author{
Sigmund Hough ${ }^{1}$
}

Published online: 3 May 2016

(C) Springer Science+Business Media New York 2016

The journal of Sexuality and Disability remains a professional home for many and a place of professional rejuvenation for still more. If you are new to the journal in 2016, we give to you a "BIG WELCOME." Over decades of contribution to the literature on sexuality and disability, we have been a part of the growth, sharing and understanding. Now most importantly, we continue to be a part of change in how we look and examine the topic, the need, and the response in terms of best practice-evidence based approaches. With the intelligence, experience, motivation and commitment from our authors, readership and editorial board, and resources and guidance from the Springer Staff, our journal's mission remains strong and meaningful.

Some of the topics in this issue, include a look at the Willowbrook State School's role in the history of disability rights movement in the United States, questionnaire survey data highlighting sexual experiences of adolescents without and with disability, sexuality educational interventions, insights into the sexual assistant in Italy, and an in-depth review of the book Supporting Disabled People with Their Sexual Lives: A Clear Guide for Health and Social Carte Professionals.

Sexuality and Disability continues to provide original impact articles addressing the mental health and medical aspects of sexuality in relation to rehabilitation, hospital, academic and community settings, publishing up-to-date articles, case studies, clinical practice reports, reviews, featured articles, historical articles, special grand rounds topics, brief research reports and survey data reports. Value benefit is provided to authors through worldwide electronic exposure and professional access, while readership gains from scholarly contributions to advance the field through research, best-practice and educational articles. The refined lens of individual contributions from the local and international community continues to deliver a wealth of information on the topic of sexuality and disability for the reader. Thank you for being a part of our professional community.

Sigmund Hough

Sigmund_Hough@hms.harvard.edu

$1 \quad 100$ Cummings Center, Suite 207, Beverly, MA 01915-6144, USA 